\title{
Reflections on Turning 40: A Historical Review of the Ottawa Valley Health Libraries Association/ l'Association des bibliothèques de la santé de la vallée de l'Outaouais
}

\author{
Kelly Farrah, Caitlyn Ford, Jessie Cunningham, and Jennifer Skuce
}

\section{Introduction}

The Ottawa Valley Health Libraries Association/ l'Association des bibliothèques de la santé de la vallée de l'Outaouais (OVHLA), originally founded in 1974 as the Ottawa-Hull Health Libraries Group (OHHLG), was one of the first Chapters of the Canadian Health Libraries Association/Association des bibliothèques de la santé du Canada (CHLA/ABSC). In 2015, OVHLA members embarked on a project to collect and preserve the Association's historical documents and to summarize and share its history. In addition to wanting to archive the Association's records and create a timeline of its key accomplishments, the current executive also wanted to review what made the Association work well in the past, to see how it has evolved over time, and to use this information to help chart a course for the future.

\section{OVHLA History Project}

The OVHLA History Project followed the examples of previous Chapter history projects from the Northern Alberta Health Libraries Association $[1,2]$ and the Manitoba Association of Health Information Providers [3]. A working group of OVHLA members used two approaches to gather information for this project: reviewing written historical records and conducting questionnairebased interviews.

Past and present OVHLA members were solicited to contribute historical records. Minutes from meetings, Chapter reports, membership lists, treasurer records, and other documents were collated and reviewed. Issues of the Journal of the Canadian Health Libraries Association and Bibliotheca Medica Canadiana were also scanned to identify information relevant to OVHLA's history.

Questionnaire-based interviews were conducted via email with six past-presidents and one long-standing
OVHLA member to gather their reflections. There were nine questions covering topics such as most memorable moments, the Association's evolution, and its main achievements and challenges.

Both the historical records and the interview responses were analyzed to develop a narrative review of OVHLA's significant moments and to identify important themes. What follows is a brief overview of the Association's origins and development (see Appendix A for a timeline of milestones in OVHLA's history). As well, the Association's activities and achievements are discussed in terms of four main themes: advocacy, resource sharing, professional development, and networking and socializing.

\section{Origins of the OHHLG}

On 6 November 1974, an informal meeting of librarians in the Ottawa-Hull area, organized by Mabel Brown and Ann Nevill, was held at the Ottawa Civic Hospital library. Thirteen staff members from ten different libraries attended. The main topics of discussion at the inaugural meeting were "the problem of coordinating monograph acquisitions in the area, and whether hospital libraries should be requested to lend heavily used books." Attendees agreed that continued meetings would be useful and decided to meet every two months. The first year was mostly spent fostering relationships and touring local health libraries. At the start of the second year in September 1975, attendees held a "re-organizational" meeting and began planning projects, electing their first Chair, Mabel Brown. Two years later in September 1977, they officially adopted the name OHHLG/ Groupe des bibliothèques de la santé d'Ottawa-Hull.

\section{"Welcome Chapter Two!"}

In January 1978, OHHLG members voted unanimously to apply for Chapter status with CHLA/ABSC. In anticipation,

Kelly Farrah, ${ }^{1}$ Caitlyn Ford, Jennifer Skuce. CADTH, 865 Carling Ave., Suite 600, Ottawa, ON K1S 5S8.

Jessie Cunningham. Canadian Medical Protective Association, 875 Carling Avenue, Ottawa, ON K1S 5P1.

${ }^{1}$ Corresponding author (email: KellyF@cadth.ca) 
the Group's name was changed to the CHLA: Ottawa-Hull Chapter/ABSC: Section de l'Outaouais, a move that was not looked upon favourably by then-president of CHLA/ABSC, Mrs. M.A. Flower. In an August 1978 letter to thenOHHLG Chairman Maurice Alarie, Flower expressed her "difficulties" with the Group's choice to name themselves as a Chapter "before the fact" and suggested they readopt their OHHLG name.

To meet CHLA/ABSC requirements for Chapter status, the Group drafted the first version of its constitution and bylaws, which were approved in March 1978. The original purpose of the Group was "to promote, by means of cooperation and communication, the provision of quality library service in the health sciences throughout the Ottawa-Hull region" and "to support the activities of the parent organization and maintain contact and share information with other Chapters and the biomedical library community as a whole."

On 18 November 1978, Flower wrote a letter of acceptance to OHHLG Chairman Alarie, announcing: "Welcome Chapter Two! The future looks bright for all of us." According to the letter, she was "impressed again with the parallelism between the aims of [the] Group and the aims of the national Association." The Group was ceremoniously awarded official Chapter status at the 1979 CHLA/ABSC annual meeting in Ottawa, hosted by the new Chapter.

\section{Name changes and formation of OVHLA}

Two years after becoming a CHLA/ABSC Chapter, in September 1980, members heeded the advice of Flower and voted to change their name back to the original OHHLG name. That name was kept until 1988, when the Chapter made a slight naming revision, becoming the Ottawa-Hull Health Libraries Association (OHHLA).

In 1994, OHHLA merged with the inactive Ontario Hospital Association Region \#9 Hospital Libraries Group. The two groups had always had a strong relationship: having similar regional boundaries, they shared many members, collaborated on continuing education (CE), and reported at each other's meetings on their activities. With the merger, the constitution and bylaws, which had been unchanged since May 1984, were reviewed and revised. Members chose a new name to reflect the merged group: Ottawa Valley Health Librarians Association/l'Association des bibliothèques de la santé de la vallée de l'Outaouais. Although the name has remained unchanged since then, the accuracy of its name has been questioned given the geographic range of its members (since 2006, some members from the inactive Kingston Area Health Libraries Association, including Bracken Health Sciences Library at Queen's University, have been members).

\section{Membership and member engagement}

As I recall, my stint as Chapter president was by acclamation, as it was hard to convince candidates to run at the time.

- Elizabeth Hawkins Brady (President 1985-1986, 1995-1997)
Despite the Association's long history and many accomplishments, low attendance at meetings and CE activities was a recurring theme in meeting minutes from all four decades. The minutes, and some comments from members interviewed, also reflected difficulties finding volunteers to fill executive positions. Lack of member involvement reached a critical point in 1983-1984, when the very existence of the OHHLG was in jeopardy. The absence of any volunteers for open executive positions led to a "survival meeting" at which the Group's future was at stake. At the March 1984 meeting, incoming CHLA/ABSC president David Crawford addressed OHHLG members, speaking about the advantages of maintaining a local Chapter. Following the talk, the Group held a vote on whether to continue and, if so, how. Members decided to carry on, but with modifications, including fewer annual meetings - two program meetings and one social meeting a year.

Since then, the issue of how to increase membership and to engage current members has remained an ongoing challenge. In particular, staff reductions and the closures of local health libraries have been a blow to Association membership. Past-president Deborah Scott-Douglas noted: "When I first joined the OVHLA, the Association was much larger and more active than it is today, reflecting the significant health science library community in Ottawa at the time. Sadly, over the years, many of these libraries have been downsized or closed."

\section{Advocacy}

The need to continually demonstrate the value and relevance of your collection and services both to the parent organization and the community at large [is] an issue that remains current today.

- Elizabeth Hawkins Brady (President 1985-1986, 1995-1997)

Amid budget constraints and library closures, the Association took on an advocacy role, speaking out against regional threats to health librarianship. The earliest example of this advocacy was March 1976, when a letter was written to the Ontario Ministry of Education to protest the rising cost of interlibrary loan borrowing. Since then, most of the Association's advocacy efforts have been directed toward fighting against library closures. Letters were written to protest library closures at the Canadian Hospital Association (1983), Ontario Hospital Association (1996), Canadian Nurses Association (1998), and Health Canada (2014).

\section{Resource sharing}

Budgets were always, and still are, an issue.

- Cathy MacLean (President 2007-2009)

Sharing resources between local libraries was another way the Association dealt with budget cuts. In 1979, for example, rising journal prices forced many local libraries to 
downsize journal subscriptions. The University of Ottawa, one of the libraries that had to make cuts, was forced to cancel $\$ 18,000$ worth of medical and scientific journals. Maurice Alarie, then director of the University's Vanier library, estimated that "the cost of medical and scientific journals [had] risen $244 \%$ over the past 10 years." OHHLG member libraries consulted with one another to ensure that journals proposed for cancellation would be available in at least one local library.

Resource sharing continued throughout the years in various forms, including reciprocal borrowing and lending among member institutions, a subcommittee for shared services among health libraries in Ottawa's Alta Vista district, and a subcommittee on local consumer health education resources in partnership with the Ottawa Public Library.

One challenge to resource sharing was the need to balance the inequality of access between larger and smaller libraries. How smaller libraries could use, without abusing, the services of larger libraries was discussed at a meeting in 1975. In 2001, with local libraries beginning to adopt DOCLINE, reciprocal agreements to guide interlibrary loans and balancing the workload among member libraries were again topics of debate.

Historically, one of the most important tools for sharing resources between members was the Union List of Serials in Ottawa-Hull Hospital Libraries. Creating this publication was one of the OHHLG's first activities, with the first edition produced in 1976. It was considered a "vital resource," especially for smaller libraries. In 1999, the first electronic version of the union list was made available via the Association's first website. With DOCLINE, generating and accessing the union list became much simpler. When an OVHLA DOCLINE code was established in 2003, a union list for local libraries could be generated automatically using SERHOLD data. With increased use of DOCLINE, and holdings becoming available online, the local union list of serials became less and less necessary.

\section{Professional development}

I think OVHLA has been fortunate to have some very experienced and forward-thinking members, several of whom have acted at a fairly senior level in shaping the Canadian health library landscape.

- Becky Skidmore (President 2001-2004)

Professional development, through informal knowledge sharing and $\mathrm{CE}$, has always been a central activity of the Association. In its earlier years, the OHHLG/OHHLA had guest speakers at every meeting, ranging from CHLA/ ABSC presidents, to the Librarian and Curator of Rare Books at Johns Hopkins University, to a panel of three local doctors discussing AIDS. Later, CE took the form of courses and presentations, including topics such as consumer health, "library applications of INTERNET," social media, and health information for immigrants and refugees. Significant CE activities in later years included a full day mini-conference in 2008, the development of a journal club in 2013, and an evening mini-symposium in 2015.
Several of the members interviewed highlighted hosting conferences as a rewarding accomplishment. The Chapter has hosted the CHLA/ABSC annual conference four times: 1979 (third annual meeting), 1989 (Capital Investments), 1998 (L'information, c'est CAPITALizing on information), and 2007 (Capitalizing on Health Partnerships). OVHLA has also twice co-hosted the Upstate New York and Ontario MLA Chapter (UNYOC) annual conference: 2004 in Ottawa (40 in 04: Energizing Resources, Services, and Our Environment) and 2012 in Cornwall (Building Bridges). These conferences were also an important source of revenue for OVHLA.

Hosting conferences, serving as executive members, and taking part in other Chapter activities were also ways for members to develop their leadership skills. Many members later took on leadership roles in CHLA/ABSC and other organizations. For example, several past members have served as president of CHLA/ABSC: founding OHHLG member Ann (Nevill) Manning (1981-1983), Beverly Brown (19931994), Jessie McGowan (2001-2002), Dianne Kharouba (2008-2009), and Lee-Anne Ufholz (2014-2015). Former OVHLA president Margaret Quirie also served as president of the Ontario Health Libraries Association (OHLA).

Additionally, four former members have been awarded Honourary Life Membership in CHLA/ABSC: Ann (Nevill) Manning (1990), Philippe Lemay (2001), Pat Johnston (2007), and Dianne Kharouba (2012).

\section{Networking and socializing}

OVHLA was most important to me when I was the sole librarian working in a research environment. The events were an important way for me to maintain a connection with my peers in the library world.

- Margaret Sampson (President 2009-2011)

Participation in the Association gave health librarians in the region a way to connect with one another, to share ideas, and to discuss common problems, all of which were of particular importance to solo librarians. It was also a way to gain exposure to different aspects of health librarianship: hospital, academic, federal, and government agency librarians mingled. Regular meetings kept members informed about staffing changes and important activities at member libraries. With advancements in technology, communication within the Association has changed; in-person meetings are fewer and a website, listserv, and Twitter account have been created.

The Association also facilitated networking opportunities with other library associations and collaborated to host events with CHLA/ABSC, the former OHA Region \#9 Hospital Libraries Group, OHLA, and UNYOC.

Connecting with local colleagues was not strictly a professional matter; membership also provided an opportunity to socialize. Annual social events were formally introduced in 1984 and have included wine and cheese events, pub nights, and potlucks. Members developed friendships and supported each other on a personal as well as professional level. According to past-president Deborah Scott-Douglas: "More than anything, I have very happy memories of 
the collegiality and support from the membership and the friendships that I developed with many of the members."

\section{Conclusion}

Reviewing OVHLA's historical records and conducting interviews with members has been a rewarding process of rediscovery and reflection for members involved in the OVHLA History Project. Looking to the future the Association's executive should focus on what made the OVHLA successful in the past: sharing resources and knowledge, developing professional and personal relationships with colleagues, collaborating with CHLA/ABSC and other library associations, and advocating on behalf of the value of health librarianship. These strengths helped OVHLA through the challenges of budget constraints, waning participation, changing technologies, and distance between members. In 2016, this description of OHHLG from the first CHLA/ABSC Newsletter from winter 1977 [4] still resonates:

We have never become a homogenous group, and we never will-but we have learned to appreciate the common denominator that links us, large and small: our effort to deliver scientific information quickly and accurately wherever needed... This willingness to communicate and cooperate has been our intangible reward.

\section{Acknowledgements}

We thank all OVHLA members who contributed archival material, time, and effort to this project. We are especially grateful to members who gave interviews in support of this work. Thank you to Kinneret Globerman for reviewing the draft.

\section{References}

1. Chatterley T, Dorgan M, Clifford C, Chan L, Varney J, Dingwall O. Harnessing history: highlighting CHLA/ABSC capacity building through the Northern Alberta Health Libraries Association (NAHLA), 1985-2007. J Can Health Libr Assoc. 2008;29(2):51-4. doi: 10.5596/c08-010.

2. Dorgan M, Chan L, Chatterley T, Clifford C, Dingwall O, Varney J. Reporting your chapter history: the process. Canadian Health Libraries Association Factsheet [Internet]. Edmonton: Northern Alberta Health Libraries Association; 2007. [cited 2016 Feb 19] Available from: https://era.library.ualberta.ca/ downloads/2f75r909h

3. Shaw-Daigle C, Demczuk L, Osterreicher A, Raynard M. A look back on the Prairie: the Manitoba Health Libraries Association / Manitoba Association of Health Information Providers (MHLA / MAHIP) chapter history project. J Can Health Libr Assoc. 2011;32(1):17-9. doi: 10.5596/c11-013.

4. Whyte E. The Ottawa-Hull Health Science Libraries Group. CHLA/ABSC Newsletter. 1977; Winter:13. 


\section{Appendix A: OVHLA historical timeline}

1974 First informal meeting.

1975 Mabel C. Brown elected as first Chair.

1976 First edition of Union List of Serials in Ottawa-Hull Hospital Libraries produced.

Henriette A. Schmidt nominated as the group's first secretary.

1977 Officially adopts the name Ottawa-Hull Health Libraries Group (OHHLG)/Groupe des bibliothèques de la santé d'Ottawa-Hull.

1978 Name changed to CHLA: Ottawa-Hull Chapter/ABSC: Section de l'Outaouais.

Constitution and bylaws drafted. Granted CHLA/ABSC chapter status.

1979 Hosts third annual CHLA/ABSC meeting in Ottawa June 13 and 14 (first time the meeting had a two-day program).

1980 Name changed back to OHHLG.

1982 Annual membership fee introduced (\$10).

1984 "Survival" meeting, where future of Chapter is voted upon. Decision to continue as a Chapter but with fewer meetings.

Revised constitution and bylaws.

Social events introduced.

1988 Name changed to Ottawa-Hull Health Libraries Association (OHHLA).

1989 Hosts 13th annual CHLA/ABSC meeting in Ottawa May 27-31 at the Château Laurier; theme is "Capital Investments."

1994 Amalgamation of the OHHLA and the Ontario Hospital Association Region \#9 Hospital Libraries Group.

Name changed to Ottawa Valley Health Libraries Association/l'Association des bibliothèques de la santé de la vallée de l'Outaouais.

Constitution and bylaws revised.

1996 Granted CHLA/ABSC development fund to finance DOCLINE project.

1998 Hosts 22nd CHLA/ABSC conference in Hull June 5-10 at the Clarion Hotel; theme is "L'information, c'est CAPITALizing on information."

1999 Electronic version of the union list of serials made available on the Chapter's first website.

2000 Annual membership fee increased to \$20.

2003 New executive position of Continuing Education Program Coordinator introduced.

OVHLA group code established in DOCLINE.

Union list automatically created using SERHOLD data.

2004 Joint UNYOC/OVHLA annual meeting held in Ottawa October 13-15 at the Delta Hotel; theme is "40 in 04: Energizing Resources, Services, and Our Environment."

OVHLA website revived and populated with content.

2006 Some members of the inactive Kingston Area Health Libraries Association, including Bracken Health Sciences Library from Queen's University, join the OVHLA.

2007 Hosts 31st annual CHLA/ABSC conference in Ottawa May 28-June 1 at the Lord Elgin Hotel/National Arts Centre; theme is "Capitalizing on Health Partnerships."

2008 Full day OVHLA mini-conference held on 28 November at the Royal Ottawa Hospital.

2011 Revision of constitution and bylaws; changes include limiting institutional membership privileges to two members of an institution, and a minimum of one meeting a year.

2012 Joint UNYOC/OVHLA annual meeting held at NAV Centre in Cornwall October 10-12; theme is "Building Bridges."

2013 Journal club launched.

2015 OVHLA mini-symposium held. 